\title{
Role of resection and adjuvant therapy in long-term disease outcomes for low-grade pediatric intramedullary spinal cord tumors
}

\author{
Raheel Ahmed, MD, PhD, ${ }^{1}$ Arnold H. Menezes, $M{ }^{2}{ }^{2}$ and James C. Torner, $\mathrm{PhD}^{3}$ \\ 1Division of Neurosurgery, The Hospital for Sick Children, Toronto, Canada; and Departments of ${ }^{2}$ Neurosurgery and \\ ${ }^{3}$ Epidemiology, University of lowa Hospitals and Clinics, lowa City, lowa
}

OBJECTIVE Surgical excision is the mainstay treatment for resectable low-grade intramedullary spinal cord tumors (IMSCTs) in the pediatric age group. Chemotherapy and radiation treatments are generally reserved for progressive or recurrent disease. Given the indolent nature of low-grade tumors and the potential side effects of these approaches, their long-term treatment benefits are unclear. The aim of the study was to determine long-term disease outcomes and the therapeutic roles of surgery and adjuvant therapies in pediatric patients with low-grade IMSCTs over an extended follow-up period.

METHODS Case records for all pediatric patients ( $<21$ years of age) with a histopathological diagnosis of low-grade IMSCT were selected over a period from January 1975 to January 2010. Outcome variables including McCormick functional grade, overall survival (OS), and progression-free survival (PFS) were analyzed with respect to demographic and treatment variables.

RESULTS Case records of 37 patients with low-grade IMSCTs were identified, with a mean follow-up duration of $12.3 \pm$ 1.4 years (range $0.5-37.2$ years). Low-grade astrocytomas were the most prevalent histological subtype $(n=22,59 \%)$. Gross-total resection (GTR) was achieved in $38 \%$ of patients $(n=14)$. Fusion surgery was required in $62 \%$ of patients with pre- or postoperative deformity (10 of 16). On presentation, functional improvement was observed in $87 \%$ and $46 \%$ of patients in McCormick Grades I and II, respectively, and in 100\%, 100\%, and $75 \%$ in Grades III, IV, and V, respectively. Kaplan-Meier PFS rates were $63 \%$ at 5 years, $57 \%$ at 10 years, and $44 \%$ at 20 years. OS rates were $92 \%$ at 5 years, $80 \%$ at 10 years, and $65 \%$ at 20 years. On multivariate analysis, shunt placement (hazard ratio [HR] $0.33, p=0.01$ ) correlated with disease progression. There was a trend toward improved 5-year PFS in patients who received adjuvant chemotherapy and radiation therapy (RT; $55 \%$ ) compared with those who did not (36\%). Patients who underwent subtotal resection (STR) were most likely to undergo adjuvant therapy (HR 7.86, $p=0.02$ ).

CONCLUSIONS This extended follow-up duration in patients with low-grade IMSCTs beyond the first decade indicates favorable long-term OS up to $65 \%$ at 20 years. GTR improved PFS and was well tolerated with sustained functional improvement in the majority of patients. Adjuvant chemotherapy and RT improved PFS in patients who underwent STR. These results emphasize the role of resection as the primary treatment approach, with adjuvant therapy reserved for patients at risk for disease progression and those with residual tumor burden.

http://thejns.org/doi/abs/10.3171/2016.5.PEDS15356

KEY WORDS intramedullary spinal cord tumor; gross-total resection; low-grade tumor; disease-free survival; spine; oncology

$\mathrm{T}$ HE majority of intramedullary spinal cord tumors (IMSCTs) in the pediatric age group are low-grade gliomas, comprising low-grade astrocytomas and ependymomas. ${ }^{14,36}$ The mainstay treatment consists of resection, with extent of resection shown to be directly correlated with disease outcomes. ${ }^{12,13,23}$ Gross-total resection
(GTR), although feasible with the advent of neurophysiological monitoring and microsurgical techniques, is associated with a risk of neurological decline..$^{25,26}$ Disease outcomes in pediatric patients, therefore, need to be assessed over a long-term follow-up period, in light of the neurological disability, risk for secondary spinal defor-

ABBREVIATIONS GTR = gross-total resection; IMSCT = intramedullary spinal cord tumor; OS = overall survival; PFS = progression-free survival; RT = radiation therapy; STR = subtotal resection.

SUBMITTED June 13,2015. ACCEPTED May 16, 2016.

INCLUDE WHEN CITING Published online July 15, 2016; DOI: 10.3171/2016.5.PEDS15356. 
mity, and natural history of slow-growing low-grade tumors. ${ }^{8,15,44,54,55}$ Hence, it is important to weigh the surgical benefits of GTR for disease control relative to quality of life and functional outcome measures over long-term follow-up.

Chemotherapy and radiation therapy (RT) are often used for the management of both high- and low-grade tumors with progressive disease. ${ }^{7,10,11,19,20}$ In contrast, the treatment indications of adjuvant chemotherapy and RT are less clear for low-grade gliomas following subtotal resection (STR), given the inherent benign natural history of the tumor.

We undertook a retrospective analysis of clinical outcomes in pediatric patients with low-grade IMSCTs, focusing on clinical factors that correlate with disease outcomes. In contrast to earlier studies,,$^{16,32,35,45,52,53}$ our extended clinical follow-up beyond the first decade allows long-term assessment of disease outcomes. We also determined clinical factors that aid in decision-making for adjuvant chemotherapy and RT.

\section{Methods}

Pediatric patients $(<21$ years of age) with a histopathological diagnosis of low-grade (Grade I or II) IMSCT were identified from the neurosurgery database at the University of Iowa Hospitals and Clinics, over a study period extending from January 1975 to January 2010. Patient records were systematically reviewed for: 1) demographics, 2) clinical presentation, 3) surgical treatment, 4) chemotherapy and/or RT received, and 5) final clinical outcomes. Pre- and postoperative clinical and radiographic evaluation were undertaken in a multidisciplinary manner by Pediatric Neurosurgery, Orthopedics, Medical Oncology, and Radiation Oncology services. Baseline and follow-up clinical and radiographic assessment of skeletal deformity, and determination and timing of skeletal fusion when needed, was undertaken in consultation with the Pediatric Orthopedics service. The senior author (A.H.M.) was the primary surgeon for the majority of patients. Computed tomography myelograms were used for radiographic diagnosis for the earlier part of the study until the time that MRI was routinely used. Pre- and postoperative functional assessment was undertaken through the modified McCormick functional scale, as previously described.,2,30,31 The deficit score on presentation was calculated through the presence (score $=1$ ) or absence (score $=0$ ) of motor, sensory, bladder, or bowel deficits. The University of Iowa Human Subjects Office Institutional Review Board approved this retrospective study.

\section{Operative Technique}

Operative techniques for pediatric IMSCTs at our institution have been described in detail previously. ${ }^{2}$ Briefly, an osteoplastic laminoplasty was planned in all children unless preoperative imaging studies indicated significant mass effect that necessitated extensive decompression. A laminectomy was performed with the aid of a fascial graft in instances when preoperative imaging studies indicated a high probability of incomplete resection, given a lack of clearly defined tumor margins. Neurophysiological moni- toring with somatosensory evoked potentials was used in the last 3 decades; motor-evoked potentials were adjuncts used in the last decade. A midline myelotomy spanned tumor segments. The initial biopsies were obtained from the most enhancing areas on preoperative MRI. Tumor dissection was aided by high-powered microscopy and a microsurgical technique with suction, ultrasonic aspiration, and cottonoid patty wisps soaked with thrombin. Bipolar cautery was infrequently needed. Circumferential dissection was then extended in all planes where a distinct tumor-spinal cord interface could be identified. Careful monitoring of the mean arterial pressure is critical (above $70 \mathrm{~mm} \mathrm{Hg}$ ), with vasopressor support as needed. Infiltrative tumors underwent significant debulking of the grossly enhancing areas, and in these situations a duraplasty was performed. In all other cases, a primary dural closure was accomplished and laminae/spinous processes were replaced. In our opinion, a laminoplasty is advantageous in aiding future instrumentation if needed, improving wound healing, and preventing CSF leak.

The degree of resection was determined through intraoperative assessment of tumor removal, additionally verified through immediate (1-3 day) postoperative MRI. Tumor resection was classified as GTR if the surgeon's and radiologist's assessments were in agreement. In all other cases, an STR was determined to have occurred.

\section{Statistical Analysis}

Univariate analysis for all outcomes analysis was performed using the Pearson chi-square test and logistic regression. Progression-free survival (PFS) and overall survival (OS) were estimated using Kaplan-Meier analysis. Multivariate analysis of survival was performed using logistic regression for dichotomous end points and survival regression using the underlying Weibull distribution for time to event analysis. Goodness of fit was assessed by survival graphs, log-survival plots, and Schoenfeld residual plots to assess proportionality. Univariate statistical associations were first calculated, and variables with $\mathrm{p}$ values $<0.1$ were then entered into a survival regression model for multivariate analysis. The proportional hazards assumption was verified. Input variables that had $p$ values $<0.05$ after this analysis were reported as statistically significant on multivariate analysis. All statistical analysis was performed using SAS software (version 9.3, SAS Inc.). Statistical significance for both univariate and multivariate analysis was set at $\mathrm{p}<0.05$.

\section{Results}

A total of 37 patients were identified with low-grade IMSCTs who received their primary or secondary treatment at the University of Iowa during the study period. Baseline demographics are summarized in Table 1. The average interval from symptom development to clinical presentation was 8.1 months (range 0.1-60 months). Sensory neurological deficits were most common $(n=29$, $78 \%)$ on presentation, followed by motor deficits $(\mathrm{n}=20$, $54 \%$ ). The cervicomedullary region was most commonly involved $(n=13,35 \%)$. Low-grade astrocytomas were the most prevalent histological subtype $(n=22,59 \%)$. 
TABLE 1. Clinical and demographic characteristics of the study population

\begin{tabular}{|c|c|}
\hline Characteristic & Value (\%) \\
\hline \multicolumn{2}{|l|}{ Age (yrs) } \\
\hline Mean \pm SEM & $10.4 \pm 1.1$ \\
\hline Range & $0.5-21$ \\
\hline \multicolumn{2}{|l|}{ Sex } \\
\hline Male & $17(46)$ \\
\hline Female & $20(54)$ \\
\hline \multicolumn{2}{|c|}{ Time from symptom onset (mos) } \\
\hline Mean \pm SEM & $8.1 \pm 1.8$ \\
\hline Range & $0.1-60$ \\
\hline Pain & $20(54)$ \\
\hline Motor deficits & $20(54)$ \\
\hline Sensory deficits & $29(78)$ \\
\hline Bladder deficits & $12(32)$ \\
\hline Bowel deficit & $6(16)$ \\
\hline \multicolumn{2}{|l|}{ Imaging findings* } \\
\hline Syrinx & $12(40)$ \\
\hline Contrast enhancement & $29(97)$ \\
\hline \multicolumn{2}{|l|}{ Margins } \\
\hline Diffuse & $21(70)$ \\
\hline Circumscribed & $9(30)$ \\
\hline \multicolumn{2}{|c|}{ No. of vertebral levels involved $†$} \\
\hline Mean \pm SEM & $5 \pm 1$ \\
\hline Range & $1-11$ \\
\hline \multicolumn{2}{|l|}{ Spinal level } \\
\hline Cervicomedullary & $13(35)$ \\
\hline Cervicothoracic $\ddagger$ & $5(14)$ \\
\hline Thoracic & $10(27)$ \\
\hline Thoracolumbar§ & $4(11)$ \\
\hline Lumbar & $5(14)$ \\
\hline \multicolumn{2}{|l|}{ Histological diagnosis } \\
\hline Astrocytoma & $22(59)$ \\
\hline Ependymoma & $8(22)$ \\
\hline Ganglioglioma & $7(19)$ \\
\hline \multicolumn{2}{|l|}{ Duration of follow-up (yrs) } \\
\hline Mean \pm SEM & $12.3 \pm 1.4$ \\
\hline Range & $0.5-37.2$ \\
\hline
\end{tabular}

${ }^{*}$ MRI studies were available for 30 patients.

$\dagger$ Levels encompassing tumor and syrinx segments.

$\ddagger$ Cervicothoracic $=$ if tumor located within the cervical or thoracic region extended to or involved the C7-T1 levels.

$\S$ Thoracolumbar $=$ if tumor located within thoracic or lumbar region extended to or involved the T11-L1 levels.

\section{Surgical Treatment and Outcomes}

The majority of patients underwent a single resection procedure during the study period $(\mathrm{n}=25,68 \%$; Table 2$)$. A spinal laminectomy was undertaken in $73 \%$ of patients $(\mathrm{n}=27)$. GTR was achieved in $38 \%$ of the patients $(\mathrm{n}=14)$. GTR rates were $18.2 \%$ for astrocytomas, $87.5 \%$ for ependymomas, and $42.9 \%$ for gangliogliomas. To determine
TABLE 2. Clinical treatment and outcomes on long-term follow-up

\begin{tabular}{|c|c|}
\hline Variable & Value (\%) \\
\hline \multicolumn{2}{|l|}{ No. of tumor surgeries } \\
\hline 1 & $25(68)$ \\
\hline 2 & $8(22)$ \\
\hline $3-4$ & $4(11)$ \\
\hline Laminectomy & $27(73)$ \\
\hline Mean no. of levels & 5 \\
\hline Range of no. of levels & $1-11$ \\
\hline Laminoplasty & $10(27)$ \\
\hline Mean no. of levels & 4 \\
\hline Range of no. of levels & $3-6$ \\
\hline \multicolumn{2}{|l|}{ Extent of resection } \\
\hline GTR & $14(38)$ \\
\hline STR & $23(62)$ \\
\hline Complications* $^{*}$ & $2(5)$ \\
\hline Shunt placement $†$ & $8(22)$ \\
\hline Recurrence or progression & $16(43)$ \\
\hline \multicolumn{2}{|c|}{ Time to recurrence or progression (yrs) } \\
\hline Mean \pm SEM & $4.3 \pm 1.4$ \\
\hline Range & $0.1-20$ \\
\hline \multicolumn{2}{|c|}{ Treatment of recurrence $(n=16) \ddagger$} \\
\hline Surgery & $8(50)$ \\
\hline Chemotherapy & $3(19)$ \\
\hline RT & $4(25)$ \\
\hline Observation & $6(38)$ \\
\hline \multicolumn{2}{|l|}{ PFS (yrs)§ } \\
\hline 5 & $63 \%$ \\
\hline 10 & $57 \%$ \\
\hline 20 & $44 \%$ \\
\hline \multicolumn{2}{|l|}{ OS (yrs)§ } \\
\hline 5 & $92 \%$ \\
\hline 10 & $80 \%$ \\
\hline 20 & $65 \%$ \\
\hline \multicolumn{2}{|c|}{$\begin{array}{l}\text { * Operative complications: wound dehiscence }(n=1) \text {, meningitis }(n=1) \text {. } \\
\text { † Shunt: ventriculoperitoneal shunt }(n=5) \text {, syrinx-subarachnoid shunt }(n=3) \text {. } \\
\text { † Treatment approaches are not mutually exclusive. } \\
\text { § The values shown are means of Kaplan-Meier product-limit estimates (see } \\
\text { text for } 95 \% \text { Cls). }\end{array}$} \\
\hline
\end{tabular}

predictors for the extent of resection, various clinical factors at presentation were evaluated. On univariate analysis, age at presentation ( $<6$ years, $6-16$ years, $>14$ years; $\mathrm{p}=0.02)$ and tumor subtype $(\mathrm{p}=0.002)$ were found to be significantly associated with the extent of resection on univariate analysis. These variables were not significant on multivariate analysis.

\section{Neurological Outcomes}

The mean follow-up duration was $12.3 \pm 1.4$ years (range 0.5-37.2 years). Comparison of functional status between initial presentation and last clinical follow-up evaluation using McCormick functional grades indicated that $87 \%$ of patients (13/15) who presented with Grade I 
status experienced neurological improvement. Of patients who presented with Grade II status $(n=13), 46 \%$ (6/13) experienced improvement in their functional state. The rates of functional improvement were 100\% (3/3) for Grade III, $100 \%$ (2/2) for Grade IV, and 75\% (3/4) for Grade V patients.

In all, 15 (75\%) of the 20 patients who presented with motor deficits experienced neurological improvement by the last follow-up evaluation. Similarly, $72 \%$ of patients (21/29) with sensory deficits on presentation showed neurological improvement. The rates for improvement in bladder and bowel deficits were 17\% (2/12) and 50\% (3/6), respectively.

The incidence of spinal deformity on presentation was $11 \%(\mathrm{n}=4)$. Postoperative deformity was present in $32 \%$ $(n=12)$ of patients at a mean interval of $1.1 \pm 0.6$ years. Fusion surgery was required in $62 \%$ of patients with deformity (10/16). The mean interval until fusion surgery was $4.3 \pm 0.9$ years (range $0.7-10$ years). More than 1 fusion procedure was required in $30 \%$ of patients $(3 / 10)$ while the remainder of the patients underwent a single fusion procedure.

\section{Long-Term Disease Outcomes}

In all, $43 \%(\mathrm{n}=16)$ of patients experienced disease recurrence or progression at a mean interval of $4.3 \pm 1.4$ years from their initial treatment. PFS was determined to be $63 \%(95 \%$ CI $45 \%-77 \%)$ at 5 years, $57 \%(95 \%$ CI $38 \%-71 \%)$ at 10 years, and $44 \%$ (95\% CI 24\%-63\%) at 20 years (Table 2, Fig. 1). OS was 92\% (95\% CI 77\%-97\%) at 5 years, $80 \%(95 \%$ CI $59 \%-91 \%)$ at 10 years, and $65 \%$ $(95 \%$ CI $37 \%-82 \%)$ at 20 years (Table 2, Fig. 1).

Disease outcomes were also stratified by extent of resection. For patients with GTR ( $=14,38 \%)$, PFS was $92 \%(95 \%$ CI $54 \%-99 \%)$ at 5 years and 10 years, and $68 \%$ (95\% CI 16\%-92\%) at 20 years. OS was $100 \%(95 \%$ CI 0 ) at 5 years, 10 years, and 20 years (Fig. 2). For the remainder of patients who underwent STR $(\mathrm{n}=23,62 \%)$ PFS was $45 \%(95 \%$ CI $24 \%-64 \%)$ at 5 years, $34 \%(95 \%$ CI $15 \%-55 \%$ ) at 10 years, and $27 \%$ (95\% CI $10 \%-48 \%$ ) at 20 years. OS was $87 \%(95 \%$ CI $64 \%-95 \%)$ at 5 years, $66 \%(95 \%$ CI $37 \%-83 \%)$ at 10 years, and $38 \%(95 \% \mathrm{CI}$ $27 \%-78 \%$ ) at 20 years (Fig. 2).

To determine predictors for OS, clinical and treatment factors were correlated with survival status (alive vs deceased). On univariate analysis, functional status on presentation, extent of resection, shunt placement, use of adjuvant therapy, indication for RT, mode of disease progression management, and number of tumor surgeries were found to correlate significantly with survival status. Shunt placement was the most significant factor on univariate analysis $(\mathrm{HR}=0.331, \mathrm{p}=0.0128)$. On multivariate analysis, none of these variables were independently associated with OS.

Using the same input variables, predictors for disease progression were similarly determined. Resection, shunt placement, use of adjuvant therapy, indication for RT, mode of disease progression management, and number of tumor surgeries correlated with disease progression on univariate analysis. On multivariate analysis, shunt placement (HR $0.33, \mathrm{p}=0.01)$ correlated with disease progression.

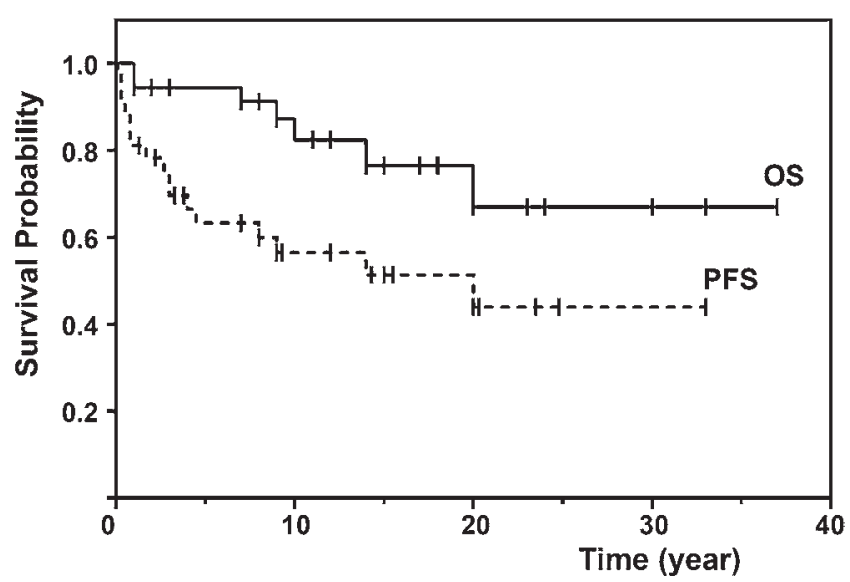

FIG. 1. Kaplan-Meier estimate of OS and PFS for all patients over the course of the study.

The impact of adjuvant therapy on disease outcomes was also assessed within the subset of patients who underwent STR. Of the 7 patients treated with chemotherapy, 3 patients underwent adjuvant therapy while 4 patients received chemotherapy for treatment of disease recurrence. Of the 15 patients who were treated with RT, 12 patients underwent adjuvant therapy while 3 patients received RT for disease recurrence. For patients who underwent STR, the inclusion of chemotherapy and RT was not significantly associated with OS. Five-year PFS showed an improved trend in patients who received adjuvant therapy following STR (55\%) as compared with patients who did not receive adjuvant therapy (36\%). However, this difference was not statistically significant ( $\mathrm{p}$ value nonsignificant).

We therefore attempted to define the treatment indications for chemotherapy and RT. Clinical and treatment factors were correlated with the use of chemotherapy and RT, retrospectively. On univariate analysis, functional grade on presentation, shunt placement, extent of resection, tumor span, and number of tumor resection surgeries were found to be significant. These factors were included in a multivariate model that showed that extent of resection was significantly associated with use of adjuvant therapy (HR 7.86, p = 0.02, 95\% CI 1.3-47.03).

\section{Discussion}

The indolent nature of low-grade pediatric IMSCTs necessitates that assessment of treatment outcomes must take into account the need for extended clinical follow-up. Our long-term follow-up duration, extending beyond the first decade, indicates favorable outcomes with OS up to $80 \%$ and PFS up to $57 \%$ at 10 years in pediatric patients with low-grade IMSCTs. Resection was well tolerated with sustained functional improvement observed in the majority of patients. The inclusion of adjuvant chemotherapy and RT for patients following an STR was associated with a trend in PFS. In addition, the extent of resection was identified retrospectively as a significant treatment criterion for adjuvant therapy. Previous reports have either pooled all histological subtype ${ }^{37}$ or both adult and pediatric patients together. ${ }^{19,28}$ Our report focuses on long-term outcomes in 
low-grade IMSCTs and retrospectively analyzes clinical factors that aid in decision-making in the use of adjuvant chemotherapy and RT.

\section{Role of Resection}

The most common subtypes of low-grade gliomas in the pediatric age group are Grades I and II astrocytomas and low-grade ependymomas. ${ }^{27,45}$ GTR rates of up to $75 \%$ have been reported for IMSCTs in pediatric patients.? Lower rates of GTR have been reported in series with a higher proportion of astrocytomas that are typically associated with infiltrative borders. ${ }^{45}$ Our results indicate that tumor subtype is strongly associated with extent of resection, with higher rates of GTR in ependymomas (87.5\%) as compared with astrocytomas (18.2\%), consistent with findings from earlier reports. ${ }^{21,24}$

GTR is recognized as the primary treatment of choice for these tumors. ${ }^{12,13,42}$ In pediatric patients with low-grade gliomas, GTR is associated with significantly prolonged $\mathrm{PFS}^{43,45,51}$ and OS. ${ }^{38}$ Yet, additional studies have reported limited benefits of GTR. The extent of resection was not found to correlate with OS within a multicenter consortium of French hospitals, with survival rates of $66 \%$ at 5 years and $60 \%$ at 10 years within this group. ${ }^{4}$ Despite varying results reported on the role of surgery, consensus evidence suggests a beneficial role of GTR in spinal lowgrade gliomas in pediatric patients. ${ }^{17}$

The ideal treatment goal of radical tumor resection must also be balanced by the potential for long-term neurological morbidity in pediatric patients. Tumor location, preoperative neurological status, and the presence of spinal deformity can further impact long-term functional and neurological outcomes following GTR of IMSCTs. ${ }^{16,44}$ Similar considerations for the morbidity of GTR in intracranial gliomas have been highlighted by reports of permanent neurological deficits in as many as $18 \%$ of pediatric patients following GTR of low-grade cerebellar astrocytomas. ${ }^{6}$

In our study group, the overall rate of GTR was $38 \%$. This rate is consistent with the preponderance of astrocytomas (59\%) in our group, that typically present with diffuse borders (70\%) and hence indistinct surgical planes of resection. Given the indolent nature of low-grade IMSCTs, our results focused on assessment of long-term disease outcomes. On extended clinical follow-up, GTR was significantly associated with improved PFS and OS. There is a clear discordance in OS and PFS rates between patients who undergo GTR and STR, respectively (Fig. 2). PFS was approximately $34 \%$ at 10 years in patients who underwent STR as compared with approximately $92 \%$ at 10 years in those who underwent GTR. OS was associated with GTR on univariate analysis $(p=0.01)$ but did not reach statistical significance on multivariate analysis, probably due to sample size limitation. Hence, our results emphasize the important role of GTR in improving long-term disease outcomes. This is concordant with clinical data on intracranial lowgrade gliomas in the pediatric age group that indicate that disease outcome measures are most significantly affected by the extent of resection. ${ }^{47}$ This finding also highlights a key difference in the natural history of intramedullary low-grade gliomas in contrast to the intracranial low-grade
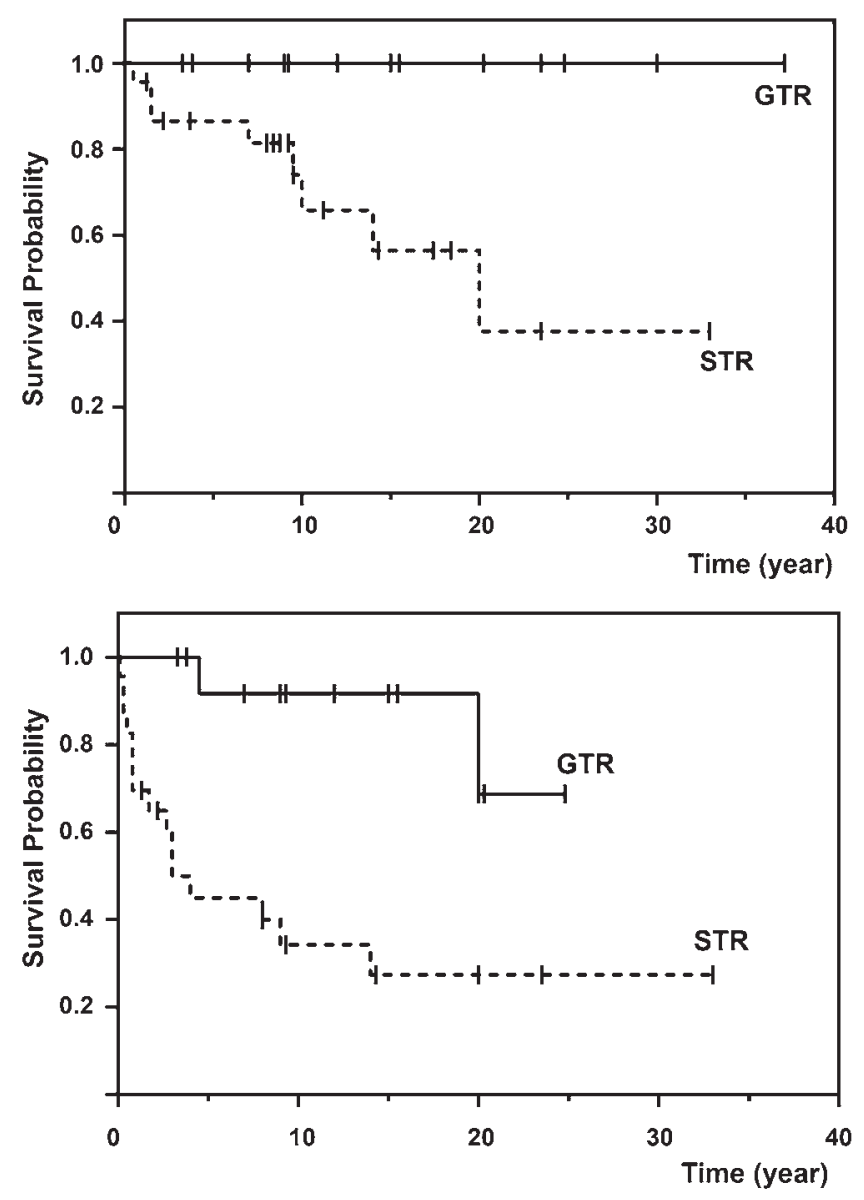

FIG. 2. Kaplan-Meier estimate of patient OS (upper) and PFS (lower) stratified by extent of resection.

gliomas that are associated with relatively better/prolonged PFS rates of $45 \%-56 \%$ following STR at 8 years. ${ }^{53}$

Our results indicate that surgery is well tolerated in the pediatric age group, and up to approximately $75 \%$ of patients experienced significant improvement in their preoperative motor and sensory deficits. The majority of patients (87\%) who presented in McCormick Grade I showed functional improvement, with up to $75 \%-100 \%$ of patients in Grades IV and $\mathrm{V}$ also experiencing functional improvement by at least 1 functional grade. In all, 27\% (10/37) of patients required a fusion surgery for associated spinal deformity that was within the reported range of secondary deformity in IMSCTs. ${ }^{8,48,55,56}$ Hence, our long-term (more than 1 decade) assessment of disease outcomes indicates significantly improved OS and PFS following GTR as compared with STR. Concurrent assessment of McCormick functional grades indicates that GTR was well tolerated with improvement and/or preservation of baseline functional status over an extended follow-up period.

\section{Role of Adjuvant Chemotherapy}

Consensus guidelines on the postoperative management use of adjuvant treatments including RT and chemotherapy are lacking, given the relatively rare incidence of these tumors and the heterogeneity within patients with 
respect to age, histology, grade, degree of resection, and tumor location. Chemotherapy treatment regimens have been proposed with the therapeutic rationale of improving disease outcomes following partial resection or disease progression, to avert long-term disease progression and delay the use of RT in newly diagnosed gliomas. ${ }^{10}$ Polychemotherapy enabled an OS rate of $87.5 \%$ over a median follow up of 4.8 years, with 4 patients $(50 \%)$ in continuous remission without the use of any RT (study group, $n=8$ ). Chemotherapy has also been effective in enabling partial response or stable disease in patients with leptomeningeal disease at onset, a subset that is typically associated with poor outcomes. ${ }^{5}$ Hence, the inclusion of chemotherapy after incomplete resection may delay or avoid the use of RT.

Chemotherapy is generally well tolerated in the majority of patients, with minimal toxicity. ${ }^{40,41}$ Hence, a conservative resection combined with adjuvant therapy has also been recommended for intramedullary low-grade astrocytomas. ${ }^{52}$ In addition, the therapeutic efficacy of chemotherapy has been reported to be comparable to radiotherapy regimens. ${ }^{45}$

\section{Role of Adjuvant RT}

Adjuvant therapy is associated with improved survival following STR for IMSCTs. ${ }^{22,38}$ Adjuvant radiotherapy following resection significantly improved PFS in a pooled sample population of patients with ependymoma. ${ }^{27} \mathrm{PFS}$ was significantly improved in patients who underwent STR followed by adjuvant RT as compared with those who underwent GTR only. ${ }^{20,27}$ Disease survival up to $59 \%$ at 5 years and $43 \%-52 \%$ at 10 years has been reported for patients with astrocytomas treated with adjuvant radiotherapy (median dose $50 \mathrm{~Gy}$ ) following biopsy or STR. ${ }^{9,20,28,34}$ In-field failure with local tumor recurrence is the most common form of disease recurrence in patients who received postoperative RT. ${ }^{1,28,33,49}$ Local failure rates for ependymomas following postoperative adjuvant RT range from $0 \%$ to $11 \% .^{22,27}$ Similarly, for low-grade astrocytomas, local failure rates range from $22 \%$ to $56 \% .^{22}$

Other studies have reported conflicting treatment experiences with adjuvant RT. Within a multicenter patient cohort, the inclusion of RT was not found to benefit OS for patients who underwent GTR or STR. ${ }^{4}$ The inclusion of postoperative RT was not associated with disease progression, nor with OS in patients with astrocytomas or ependymomas. ${ }^{1}$

RT in pediatric patients with IMSCTs is complicated by both the toxicity and long-term sequelae induced by radiation. These sequelae include development of secondary malignancy, ${ }^{37}$ secondary anaplastic changes, ${ }^{9}$ increased risk of secondary spinal deformity, ${ }^{39}$ and radiation-induced myelitis. ${ }^{29}$ Myelotoxicity of RT is related to the dose per daily fraction, and the location and length of cord segment that is irradiated. ${ }^{22}$ High-dose RT up to $50 \mathrm{~Gy}$ over large treatment fields can be associated with risks of radiation-induced deficits, including spastic quadriplegia. ${ }^{52} \mathrm{Ra}-$ diation doses in the 5500-6000-cGy range are associated with a $6 \%$ risk of radiation myelitis. ${ }^{29}$ Pediatric patients are more susceptible and radiation-induced myelopathy is often observed at lower doses. The neurocognitive effects of radiation and secondary myelopathy are apparent in children at lower doses than in adults. ${ }^{46,50}$

\section{Treatment Indications of Chemotherapy and RT}

The treatment rationales for chemotherapy and RT are more clearly defined for high-grade IMSCTs and for patients with low-grade tumors with typically diffuse and surgically unresectable tumors that show disease progression. ${ }^{3,10,18}$ In contrast, the treatment indications for chemotherapy and RT are less well defined for patients with low-grade tumors following an STR, when expectant management by clinical observation must be weighed against the treatment option of chemotherapy and RT for adjuvant indications or for treatment of disease recurrence at a later time point.

Given PFS rates following STR of $45 \%$ and $34 \%$ at 5 years and 10 years, respectively, it is important to identify clinical parameters that can predict at-risk subgroups that would benefit from adjuvant therapies. In our study, we therefore focused on identifying clinical factors that aid in decision-making for inclusion of chemotherapy and RT following an STR. Our results indicate that the inclusion of adjuvant chemotherapy and RT was more likely in patients with residual tumor burden following STR. Thus, patients with extensive IMSCTs that were partially resected were more likely to receive chemotherapy or RT. This clinical factor will aid in treatment decisions for adjuvant therapy following STR. The mean interval until disease progression was more than 4 years in our series, underscoring the need for long-term follow-up and surveillance imaging in postoperative management of pediatric patients with lowgrade IMSCTs.

\section{Conclusions}

Our results indicate that on extended long-term followup, surgical management of low-grade pediatric IMSCTs is associated with favorable neurological and disease outcome measures. GTR enables improvement in OS and PFS. The addition of adjuvant chemotherapy and RT following STR is associated with an improved trend in PFS. Residual tumor disease following STR is most significantly associated with use of adjuvant chemotherapy and RT.

\section{References}

1. Abdel-Wahab M, Etuk B, Palermo J, Shirato H, Kresl J, Yapicier O, et al: Spinal cord gliomas: A multi-institutional retrospective analysis. Int J Radiat Oncol Biol Phys 64:10601071,2006

2. Ahmed R, Menezes AH, Awe OO, Torner JC: Long-term disease and neurological outcomes in patients with pediatric intramedullary spinal cord tumors. J Neurosurg Pediatr 13:600-612, 2014

3. Balmaceda C: Chemotherapy for intramedullary spinal cord tumors. J Neurooncol 47:293-307, 2000

4. Bouffet E, Pierre-Kahn A, Marchal JC, Jouvet A, Kalifa C, Choux M, et al: Prognostic factors in pediatric spinal cord astrocytoma. Cancer 83:2391-2399, 1998

5. Chamberlain MC: Leptomeningeal metastasis. Curr Opin Oncol 22:627-635, 2010

6. Cochrane DD, Gustavsson B, Poskitt KP, Steinbok P, Kestle JR: The surgical and natural morbidity of aggressive resection for posterior fossa tumors in childhood. Pediatr Neurosurg 20:19-29, 1994

7. Constantini S, Miller DC, Allen JC, Rorke LB, Freed D, Epstein FJ: Radical excision of intramedullary spinal cord 
tumors: surgical morbidity and long-term follow-up evaluation in 164 children and young adults. J Neurosurg 93 (2 Suppl):183-193, 2000

8. de Jonge T, Slullitel H, Dubousset J, Miladi L, Wicart P, Illés T: Late-onset spinal deformities in children treated by laminectomy and radiation therapy for malignant tumours. Eur Spine J 14:765-771, 2005

9. Dirks PB, Jay V, Becker LE, Drake JM, Humphreys RP, Hoffman HJ, et al: Development of anaplastic changes in low-grade astrocytomas of childhood. Neurosurgery 34:6878, 1994

10. Doireau V, Grill J, Zerah M, Lellouch-Tubiana A, Couanet $\mathrm{D}$, Chastagner P, et al: Chemotherapy for unresectable and recurrent intramedullary glial tumours in children. Br $\mathbf{J}$ Cancer 81:835-840, 1999

11. Duffner PK, Krischer JP, Burger PC, Cohen ME, Backstrom JW, Horowitz ME, et al: Treatment of infants with malignant gliomas: the Pediatric Oncology Group experience. J Neurooncol 28:245-256, 1996

12. Epstein F: Spinal cord astrocytomas of childhood. Adv Tech Stand Neurosurg 13:135-169, 1986

13. Epstein F, Epstein N: Surgical treatment of spinal cord astrocytomas of childhood. A series of 19 patients. J Neurosurg 57:685-689, 1982

14. Epstein FJ, Farmer JP: Pediatric spinal cord tumor surgery. Neurosurg Clin N Am 1:569-590, 1990

15. Fassett DR, Clark R, Brockmeyer DL, Schmidt MH: Cervical spine deformity associated with resection of spinal cord tumors. Neurosurg Focus 20(2):E2, 2006

16. Garcés-Ambrossi GL, McGirt MJ, Mehta VA, Sciubba DM, Witham TF, Bydon A, et al: Factors associated with progression-free survival and long-term neurological outcome after resection of intramedullary spinal cord tumors: analysis of 101 consecutive cases. J Neurosurg Spine 11:591-599, 2009

17. Goh KY, Velasquez L, Epstein FJ: Pediatric intramedullary spinal cord tumors: is surgery alone enough? Pediatr Neurosurg 27:34-39, 1997

18. Grill J, Le Deley MC, Gambarelli D, Raquin MA, Couanet D, Pierre-Kahn A, et al: Postoperative chemotherapy without irradiation for ependymoma in children under 5 years of age: a multicenter trial of the French Society of Pediatric Oncology. J Clin Oncol 19:1288-1296, 2001

19. Huddart R, Traish D, Ashley S, Moore A, Brada M: Management of spinal astrocytoma with conservative surgery and radiotherapy. Br J Neurosurg 7:473-481, 1993

20. Hulshof MC, Menten J, Dito JJ, Dreissen JJ, van den Bergh $\mathrm{R}$, González González D: Treatment results in primary intraspinal gliomas. Radiother Oncol 29:294-300, 1993

21. Innocenzi G, Raco A, Cantore G, Raimondi AJ: Intramedullary astrocytomas and ependymomas in the pediatric age group: a retrospective study. Childs Nerv Syst 12:776-780, 1996

22. Isaacson SR: Radiation therapy and the management of intramedullary spinal cord tumors. J Neurooncol 47:231-238, 2000

23. Jallo GI, Danish S, Velasquez L, Epstein F: Intramedullary low-grade astrocytomas: long-term outcome following radical surgery. J Neurooncol 53:61-66, 2001

24. Karikari IO, Nimjee SM, Hodges TR, Cutrell E, Hughes BD, Powers CJ, et al: Impact of tumor histology on resectability and neurological outcome in primary intramedullary spinal cord tumors: a single-center experience with 102 patients. Neurosurgery 68:188-197, 2011

25. Klekamp J: Treatment of intramedullary tumors: analysis of surgical morbidity and long-term results. J Neurosurg Spine 19:12-26, 2013

26. Kothbauer K, Deletis V, Epstein FJ: Intraoperative spinal cord monitoring for intramedullary surgery: an essential adjunct. Pediatr Neurosurg 26:247-254, 1997
27. Kukreja S, Ambekar S, Sin AH, Nanda A: Cumulative survival analysis of patients with spinal myxopapillary ependymomas in the first 2 decades of life. J Neurosurg Pediatr 13:400-407, 2014

28. Linstadt DE, Wara WM, Leibel SA, Gutin PH, Wilson CB, Sheline GE: Postoperative radiotherapy of primary spinal cord tumors. Int J Radiat Oncol Biol Phys 16:1397-1403, 1989

29. Marcus RB Jr, Million RR: The incidence of myelitis after irradiation of the cervical spinal cord. Int J Radiat Oncol Biol Phys 19:3-8, 1990

30. McCormick PC, Stein BM: Intramedullary tumors in adults. Neurosurg Clin N Am 1:609-630, 1990

31. McGirt MJ, Chaichana KL, Atiba A, Attenello F, Woodworth GF, Jallo GI: Neurological outcome after resection of intramedullary spinal cord tumors in children. Childs Nerv Syst 24:93-97, 2008

32. McGirt MJ, Chaichana KL, Atiba A, Attenello F, Yao KC, Jallo GI: Resection of intramedullary spinal cord tumors in children: assessment of long-term motor and sensory deficits. J Neurosurg Pediatr 1:63-67, 2008

33. McLaughlin MP, Buatti JM, Marcus RB Jr, Maria BL, Mickle PJ, Kedar A: Outcome after radiotherapy of primary spinal cord glial tumors. Radiat Oncol Investig 6:276-280, 1998

34. McLaughlin MP, Marcus RB Jr, Buatti JM, McCollough WM, Mickle JP, Kedar A, et al: Ependymoma: results, prognostic factors and treatment recommendations. Int J Radiat Oncol Biol Phys 40:845-850, 1998

35. Merchant TE, Kiehna EN, Thompson SJ, Heideman R, Sanford RA, Kun LE: Pediatric low-grade and ependymal spinal cord tumors. Pediatr Neurosurg 32:30-36, 2000

36. Miller DC: Surgical pathology of intramedullary spinal cord neoplasms. J Neurooncol 47:189-194, 2000

37. O'Sullivan C, Jenkin RD, Doherty MA, Hoffman HJ, Greenberg ML: Spinal cord tumors in children: long-term results of combined surgical and radiation treatment. J Neurosurg 81:507-512, 1994

38. Oh MC, Ivan ME, Sun MZ, Kaur G, Safaee M, Kim JM, et al: Adjuvant radiotherapy delays recurrence following subtotal resection of spinal cord ependymomas. Neuro Oncol 15:208-215, 2013

39. Otsuka NY, Hey L, Hall JE: Postlaminectomy and postirradiation kyphosis in children and adolescents. Clin Orthop Relat Res (354):189-194, 1998

40. Packer RJ, Lange B, Ater J, Nicholson HS, Allen J, Walker $\mathrm{R}$, et al: Carboplatin and vincristine for recurrent and newly diagnosed low-grade gliomas of childhood. J Clin Oncol 11:850-856, 1993

41. Pons MA, Finlay JL, Walker RW, Puccetti D, Packer RJ, McElwain M: Chemotherapy with vincristine (VCR) and etoposide (VP-16) in children with low-grade astrocytoma. J Neurooncol 14:151-158, 1992

42. Rossitch E Jr, Zeidman SM, Burger PC, Curnes JT, Harsh C, Anscher M, et al: Clinical and pathological analysis of spinal cord astrocytomas in children. Neurosurgery 27:193-196, 1990

43. Safaee M, Oh MC, Kim JM, Aranda D, Tarapore PE, Cage TA, et al: Histologic grade and extent of resection are associated with survival in pediatric spinal cord ependymomas. Childs Nerv Syst 29:2057-2064, 2013

44. Sandalcioglu IE, Gasser T, Asgari S, Lazorisak A, Engelhorn T, Egelhof T, et al: Functional outcome after surgical treatment of intramedullary spinal cord tumors: experience with 78 patients. Spinal Cord 43:34-41, 2005

45. Scheinemann K, Bartels U, Huang A, Hawkins C, Kulkarni $\mathrm{AV}$, Bouffet E, et al: Survival and functional outcome of childhood spinal cord low-grade gliomas. Clinical article. J Neurosurg Pediatr 4:254-261, 2009

46. Schultheiss TE, Kun LE, Ang KK, Stephens LC: Radiation 
response of the central nervous system. Int J Radiat Oncol Biol Phys 31:1093-1112, 1995

47. Shaw EG, Wisoff JH: Prospective clinical trials of intracranial low-grade glioma in adults and children. Neuro Oncol 5:153-160, 2003

48. Shikata J, Yamamuro T, Shimizu K, Saito T: Combined laminoplasty and posterolateral fusion for spinal canal surgery in children and adolescents. Clin Orthop Relat Res (259):9299, 1990

49. Shirato H, Kamada T, Hida K, Koyanagi I, Iwasaki Y, Miyasaka K, et al: The role of radiotherapy in the management of spinal cord glioma. Int J Radiat Oncol Biol Phys 33:323328,1995

50. Sundaresan N, Gutierrez FA, Larsen MB: Radiation myelopathy in children. Ann Neurol 4:47-50, 1978

51. Timmermann B, Kortmann RD, Kühl J, Meisner C, Slavc I, Pietsch T, et al: Combined postoperative irradiation and chemotherapy for anaplastic ependymomas in childhood: results of the German prospective trials HIT 88/89 and HIT 91. Int J Radiat Oncol Biol Phys 46:287-295, 2000

52. Townsend N, Handler M, Fleitz J, Foreman N: Intramedullary spinal cord astrocytomas in children. Pediatr Blood Cancer 43:629-632, 2004

53. Wisoff JH, Sanford RA, Heier LA, Sposto R, Burger PC, Yates AJ, et al: Primary neurosurgery for pediatric low-grade gliomas: a prospective multi-institutional study from the Children's Oncology Group. Neurosurgery 68:1548-1555, 2011

54. Woodworth GF, Chaichana KL, McGirt MJ, Sciubba DM, Jallo GI, Gokaslan Z, et al: Predictors of ambulatory function after surgical resection of intramedullary spinal cord tumors. Neurosurgery 61:99-106, 2007

55. Yao KC, McGirt MJ, Chaichana KL, Constantini S, Jallo GI: Risk factors for progressive spinal deformity following resection of intramedullary spinal cord tumors in children: an analysis of 161 consecutive cases. J Neurosurg 107 (6 Suppl):463-468, 2007

56. Yasuoka S, Peterson HA, MacCarty CS: Incidence of spinal column deformity after multilevel laminectomy in children and adults. J Neurosurg 57:441-445, 1982

\section{Disclosures}

The authors report no conflict of interest concerning the materials or methods used in this study or the findings specified in this paper.

\section{Author Contributions}

Conception and design: Menezes, Ahmed. Acquisition of data: Ahmed. Analysis and interpretation of data: all authors. Drafting the article: Menezes, Ahmed. Critically revising the article: all authors. Reviewed submitted version of manuscript: all authors. Approved the final version of the manuscript on behalf of all authors: Menezes. Statistical analysis: Ahmed, Torner. Study supervision: Menezes

\section{Supplemental Information}

\section{Previous Presentations}

Portions of this work were presented as a poster at the AANS Annual Meeting in 2013.

\section{Correspondence}

Arnold H. Menezes, Department of Neurosurgery, University of Iowa Hospitals and Clinics, 200 Hawkins Dr., 1824 JPP, Iowa City, IA 52242. email: arnold-menezes@uiowa.edu. 